\section{Endoscopic mediastinal debridement for mediasti- nitis resulting from upper esophageal perforation}

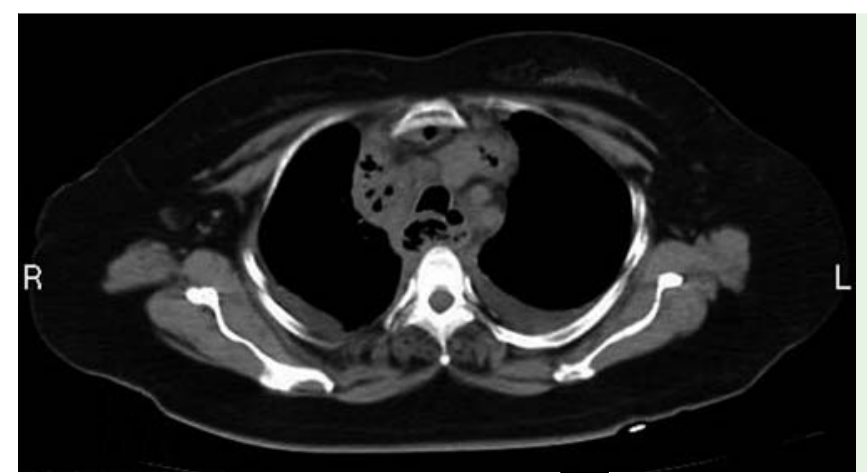

Fig. 1 Contrastenhanced computed tomography image showing extensive

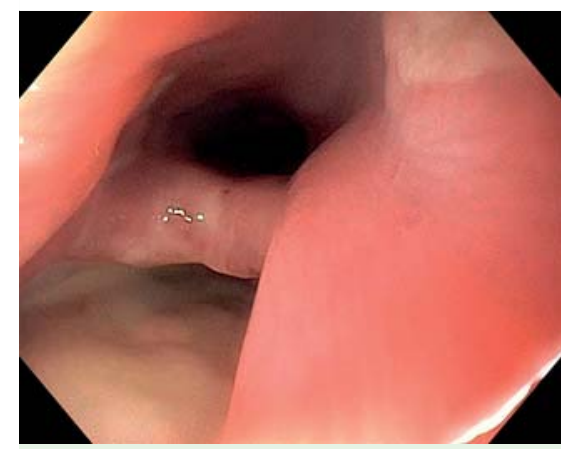

Fig. 2 Endoscopic image of the perforation site just below the cricopharynx.
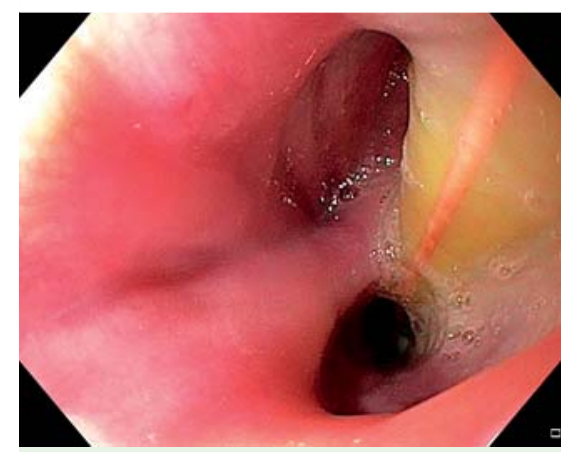

Fig. 4 Endoscopic placement of Ryles tube into the mediastinum for drainage.

A 57-year-old woman was admitted to the intensive care unit with a 15-day history of sore throat, neck pain, upper backache, and fever following the ingestion of a tablet. Initial conservative management did not resolve the symptoms and a contrast-enhanced computed tomography (CECT) scan of the chest was performed. The scan revealed posterior mediastinitis ( $\bullet$ Fig. 1), secondary to upper esophageal perforation with bilateral pleural effusion. An endoscopic assessment revealed a

Endoscopic mediastinal debridement for mediastinitis resulting from upper esophageal perforation. bridement was not complete. mediastinitis.

by endoscopic mediastinal debridement ( $\bullet$ Fig. 3, Video 1) using a standard 9.5-mm upper gastrointestinal endoscope, with suction, saline lavage, and biopsy forceps for the removal of necrotic material. The entire procedure took about 40 minutes. A nasomediastinal drainage tube (Ryles tube, $16 \mathrm{Fr}$ ) was then placed using a guidewire ( $\bullet$ Fig. 4 ). The patient was kept nil per os, and PEG feeds were started after 48 hours. Broad spectrum antibiotics were continued.

The patient underwent further repeat endoscopic procedures at 3 days, and 1, 2, 3 , and 5 weeks. At 5 weeks, endoscopy showed complete closure of the perforation site, and CECT chest ( $\bullet$ Fig. 5) showed near complete resolution of mediastinitis and pleural effusion. To date, the patient has been followed for more than 6 months, and has been symptom free.

Mediastinitis secondary to esophageal perforation is a dreaded disease with high morbidity and mortality. The majority of patients need surgical intervention in the form of thoracotomy/thoracoscopy and esophageal repair if the condition is presented early, or esophageal diversion if presentation is late. Often the recovery is prolonged and involves multiple procedures. Endoscopic mediastinal debridement through the perforation site is a novel method of minimally invasive procedure for such cases, with minimal morbidity and good post-procedure recovery. Review of the literature shows only one case series, involving a single center and 20 cases, with the procedure being performed safely and effectively [1]. The current report describes a further case managed at a tertiary care hospital.

\section{Endoscopy_UCTN_Code_TTT_1AO_2AI}

\section{Competing interests: None}

large perforation just below the cricopharynx in the posterior wall ( $\bullet$ Fig. 2 ), with discharge of copious amount of pus. Surgical opinion was sought. The patient provided informed consent following explanation of the option of surgical drainage by thoracoscopy if endoscopic de-

The following day under sedation with anesthetic monitoring, the patient underwent placement of a percutaneous endoscopic gastrostomy (PEG) tube, followed

\section{Sadashivayya S. Soppimath, Srishail Chiniwalar, Basavanandaswami Hartimath, Praveen Padasali}

Department of General Surgery and Surgical Gastroenterology, Suchirayu Hospital, Hubballi, Karnataka, India

\section{Reference}

1 Wehrmann T, Stergiou N, Vogel B et al. Endoscopic debridement of paraesophageal, mediastinal abscesses: a prospective case series. Gastrointest Endosc 2005; 62: $344-$ 349 


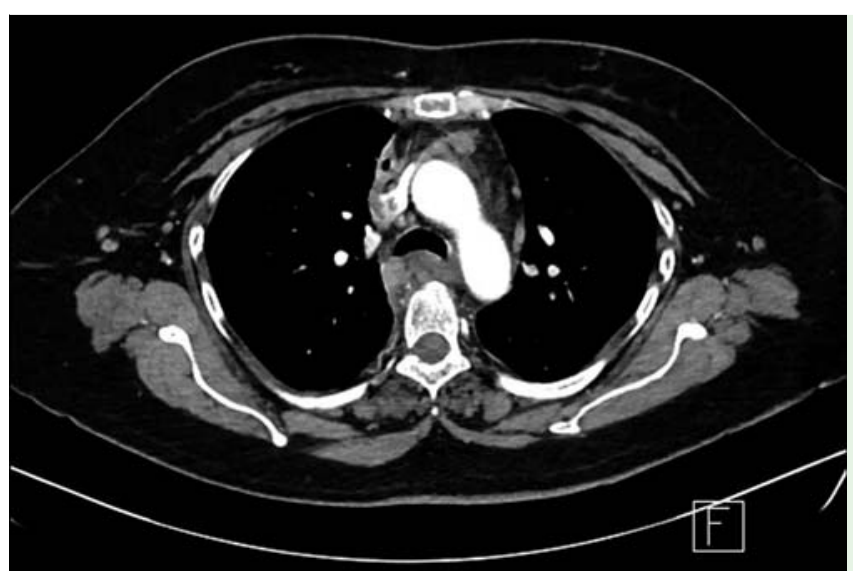

Fig. 5 Contrastenhanced computed tomography showing resolution of the mediastinitis.

\section{Bibliography}

Dol http://dx.doi.org/

10.1055/s-0042-105562

Endoscopy 2016; 48: E168-E169

(C) Georg Thieme Verlag KG

Stuttgart · New York

ISSN 0013-726X

Corresponding author Srishail Chiniwalar, DNB(SGE)

Department of General Surgery and Surgical Gastroenterology

R. No 117, First floor

Suchirayu Hospital

Gokul Road

Hubballi - 580030

Karnataka

India

Fax: +91-836-2239000

drsrichinni@gmail.com 